\title{
Clinically applied procedures for human ovarian tissue cryopreservation result in different levels of efficacy and efficiency
}

\author{
Lobke Bastings $^{1}$ • Johan R. Westphal ${ }^{1}$ - Catharina C. M. Beerendonk ${ }^{1}$. \\ Ruud L. M. Bekkers ${ }^{1}$ - Petra L. M. Zusterzeel ${ }^{1}$ • Jan C. M. Hendriks ${ }^{2}$ • \\ Didi D. M. Braat ${ }^{1} \cdot$ Ronald Peek $^{1}(D)$
}

Received: 11 July 2016 / Accepted: 15 September 2016 / Published online: 6 October 2016

(C) The Author(s) 2016. This article is published with open access at Springerlink.com

\begin{abstract}
Purpose Different protocols are being used worldwide for the cryopreservation of human ovarian tissue for fertility preservation purposes. The efficiency and efficacy of the majority of these protocols has not been extensively evaluated, possibly resulting in sub-optimally cryopreserved ovarian tissue. To address the impact of this issue, we assessed the effects of two clinically successful human ovarian tissue slow-freezing cryopreservation procedures on the quality of the cryopreserved tissue.

Methods To differentiate between cryopreservation ( ${ }_{\mathrm{C}}$ ) versus thawing $\left(_{T}\right.$ ) related effects, four combinations of these two (A and $B$ ) very different cryopreservation/thawing protocols $\left(A_{C} A_{T}, A_{C} B_{T}, B_{C} A_{T}, B_{C} B_{T}\right)$ were studied. Before and after cryopreservation and thawing, the percentage of living and morphologically normal follicles, as well as the overall tissue viability, was assessed.

Results Our experiments revealed that the choice of the cryopreservation protocol noticeably affected the overall tissue viability and percentage of living follicles, with a higher viability after protocol $\mathrm{B}_{\mathrm{C}}$ when compared to $\mathrm{A}_{\mathrm{C}}$. No statistically significant differences in tissue viability were observed between the two thawing protocols, but thawing protocol $\mathrm{B}_{\mathrm{T}}$
\end{abstract}

Capsule Our results indicate that extensive and systematical evaluation of clinically used protocols is warranted.

Ronald Peek

Ronald.Peek@Radboudumc.nl

1 Department of Obstetrics and Gynecology, Radboud University Medical Center, PO Box 9101, 6500 HB Nijmegen, The Netherlands

2 Department for Health Evidence, Section Biostatistics, Radboud University Medical Center, PO Box 9101, 6500

HB Nijmegen, The Netherlands required considerably more human effort and materials than thawing protocol $\mathrm{A}_{\mathrm{T}}$. Tissue morphology was best retained using the $\mathrm{B}_{\mathrm{C}} \mathrm{A}_{\mathrm{T}}$ combination.

Conclusion Our results indicate that extensive and systematical evaluation of clinically used protocols is warranted.

Keywords Ovarian tissue $\cdot$ Cryopreservation $\cdot$ Fertility preservation $\cdot$ Efficiency $\cdot$ Efficacy

\section{Introduction}

The survival of pediatric, adolescent, and young adult cancer patients has significantly improved during the past decades [1]. As a consequence, the attention to issues related to quality of life after cancer has increased in oncological care. With many types of oncological therapy posing a threat to the ovarian function [2], techniques aimed at preserving fertility in girls and young women have emerged and evolved [3]. In this paper, we focus on the cryopreservation of ovarian tissue. In prepubertal girls, and in women who cannot delay the start of chemotherapy, this is the only available option for fertility preservation $[4,5]$. The ovarian tissue is obtained before start of the gonadotoxic anti-cancer therapy and can be autotransplanted to the patient after she has been cured of her disease, to restore her fertility. In three major European centers for fertility preservation, a pregnancy rate of $27 \%$ was reported after autotransplantation of ovarian tissue, and more than 60 babies have been born worldwide [5-7].

The freezing/thawing protocol used for cryopreservation of the ovarian tissue is most likely to be an important factor in determining the clinical outcome (i.e., live birth) of ovarian tissue autotransplantation. Several laboratory procedures that have led to the birth of healthy children have been published [8-17]. 
The mere fact that children were born using a certain protocol, however, does not automatically imply that this protocol had been optimized to its maximum potential. In other words, tweaking the protocol might have led to an even higher success rate. To address this matter, we compared the impact of two clinically successful, but methodologically very different freezing and thawing laboratory procedures on the quality of the cryopreserved tissue. To determine the contribution of the freezing and the thawing procedure on the human ovarian tissue quality, we analyzed the effects of these events separately.

\section{Materials and methods}

\section{Study design and eligibility criteria}

The effects of the two selected cryopreservation and thawing protocols: protocol $\mathrm{A}_{\mathrm{C}} \mathrm{A}_{\mathrm{T}}$ using ethylene glycol as cryoprotectant $[18,19]$ and $\mathrm{B}_{\mathrm{C}} \mathrm{B}_{\mathrm{T}}$ using DMSO as cryoprotectant $[13$, $20,21]$ on overall ovarian tissue's viability, follicle viability, and tissue morphology were investigated in a four-arm design:

- $\mathrm{A}_{\mathrm{C}} \mathrm{A}_{\mathrm{T}}$ : cryopreservation and thawing protocol A

- $\mathrm{B}_{\mathrm{C}} \mathrm{B}_{\mathrm{T}}$ : cryopreservation and thawing protocol $\mathrm{B}$

- $\mathrm{A}_{\mathrm{C}} \mathrm{B}_{\mathrm{T}}$ : cryopreservation protocol $\mathrm{A}$ followed by thawing protocol B

- $\mathrm{B}_{\mathrm{C}} \mathrm{A}_{\mathrm{T}}$ : cryopreservation protocol $\mathrm{B}$ followed by thawing protocol A

For ethical reasons, we could not use tissue from young cancer patients applying for ovarian tissue cryopreservation. We therefore used ovarian tissue from premenopausal women aged $\leq 45$ years who were considered eligible for this prospective cohort study if they underwent a prophylactic laparoscopic salpingo-oophorectomy at the Radboud university medical center (Radboudumc), Nijmegen, the Netherlands. Informed consent was obtained prior to surgery. When possible, cortex tissue from each patient was included in all four arms of the study. In addition, a fresh (positive) control was analyzed for each patient before cryopreservation/thawing. In case of insufficient material (due to size of the ovary, presence of large follicles, and/or extensive damage as a result of cauterization during surgery), the cortex tissue of a given patient was only used in three or less of the study arm protocols.

\section{Ethical approval}

All study procedures were approved by the Radboudumc local ethics committee.

\section{Ovarian tissue preparation}

At the operating theater, the ovary dissected during surgery was collected in cold Custodiol $\left(4^{\circ} \mathrm{C}\right.$; Dr. Franz Köhler Chemie $\mathrm{GmbH}$, Bensheim, Germany). The ovary was immediately transferred to the laboratory (within 5-10 min), where it was placed on a pre-cooled surface $\left(0^{\circ} \mathrm{C}\right)$. The medulla was removed from the cortex using precision forceps and scalpels, after which ovarian cortex fragments of approximately $5 \mathrm{~mm}$ in length, $5 \mathrm{~mm}$ in width, and $1.0-1.5 \mathrm{~mm}$ in depth were prepared. These $5 \times 5 \times 1 \mathrm{~mm}$ fragments were subsequently used to prepare 3-mm-diameter punch biopsies for the glucose uptake assay (overall tissue viability) and for preparing small tissue fragments for the neutral red stain (follicle viability).

\section{Ovarian tissue cryopreservation and thawing}

The ovarian tissue cryopreservation and thawing protocols selected for this study differ considerably. Briefly, protocol A consists of a cryopreservation protocol using ethylene glycol combined with a thawing protocol based on three consecutive short washes to remove the cryoprotectant. Protocol B uses dimethyl sulfoxide (DMSO) as a cryoprotectant and has a significantly longer and more elaborate thawing procedure based on continuous dilution. Tissue was stored in liquid nitrogen for at least 1 week before thawing.

As we combined two clinically used protocols in our study, we measured the osmolality of the four cryopreservation and thawing solutions in order to determine any additional osmotic stress to which the tissue was exposed when applying cryopreservation and thawing solutions from different protocols.

\section{Cryopreservation protocol $\mathbf{A}_{\mathbf{C}}$}

Tissue fragments were equilibrated in $30 \mathrm{~mL}$ of cryomedium, consisting of $0.1 \mathrm{~mol} / \mathrm{L}$ sucrose (Sigma-Aldrich, Zwijndrecht, the Netherlands) and $1.5 \mathrm{~mol} / \mathrm{L}$ ethylene glycol (Merck Millipore, Schiphol-Rijk, the Netherlands) in phosphatebuffered saline (PBS; Braun, Melsungen, Germany) for $30 \mathrm{~min}$ on a tilting table at $4{ }^{\circ} \mathrm{C}$. Instead of using a Planer Freezer (Planer K10; Planer Ltd, UK), ovarian cortical fragments were frozen in Nunc CryoTubes (Sigma-Aldrich, St. Louis, MO, USA) in $1 \mathrm{~mL}$ cryomedium in a CryoLogic programmable temperature controller (CL-3300, Cryosolutions, 's Hertogenbosch, the Netherlands) using Cryogenesis ${ }^{\mathrm{TM}}$ V5 software (Cryosolutions). CryoTubes were transferred to the CryoLogic set at $0{ }^{\circ} \mathrm{C}$. Subsequently, the temperature was lowered at a rate of $2{ }^{\circ} \mathrm{C} / \mathrm{min}$ until a temperature of $-9{ }^{\circ} \mathrm{C}$ was reached. At this stage, CryoTubes were seeded manually with a cotton swab dipped in liquid nitrogen. The temperature remained at $-9{ }^{\circ} \mathrm{C}$ for 10 min after which seeding was checked. Next, the temperature was decreased at a rate of $0.3{ }^{\circ} \mathrm{C} / \mathrm{min}$ to $-40{ }^{\circ} \mathrm{C}$ and subsequently with $8.5^{\circ} \mathrm{C} / \mathrm{min}$ to 
$-120^{\circ} \mathrm{C}$ before the CryoTubes was stored in liquid nitrogen. This freezing protocol was comparable to the original protocol, expect for the duration at which the temperature remained at $-9{ }^{\circ} \mathrm{C}(5$ versus $10 \mathrm{~min})$ and the speed at which the temperature was lowered after reaching $-40{ }^{\circ} \mathrm{C}\left(8.5{ }^{\circ} \mathrm{C} / \mathrm{min}\right.$ to $-120^{\circ} \mathrm{C}$ versus $10^{\circ} \mathrm{C} / \mathrm{min}$ to $-140^{\circ} \mathrm{C}$ in the original protocol; [18]). The cryomedium had an osmolality of $2.3 \mathrm{Osmol} / \mathrm{kg}$.

\section{Thawing protocol $\mathbf{A}_{\mathbf{T}}$}

Tissue was thawed rapidly at $37^{\circ} \mathrm{C}$ and then rinsed in $25 \mathrm{~mL}$ of three solutions (PBS containing $0.25 \mathrm{~mol} / \mathrm{L}$ sucrose and $0.75 \mathrm{~mol} / \mathrm{L}$ ethylene glycol; PBS containing $0.25 \mathrm{~mol} / \mathrm{L}$ sucrose; and PBS, respectively) for 10 min each under continuous agitation to wash out the cryoprotectant. The first washing solution had an osmolality of $1.5 \mathrm{Osmol} / \mathrm{kg}$. In total, this resulted in a thawing procedure of approximately $35 \mathrm{~min}$.

\section{Cryopreservation protocol $\mathrm{B}_{\mathrm{C}}$}

According to cryopreservation protocol $\mathrm{B}_{\mathrm{C}}[13,20,21]$, a freezing solution with an osmolality of $2.1 \mathrm{Osmol} / \mathrm{kg}$ was prepared consisting of Leibovitz's L-15 GlutaMAX cryomedium (Gibco, Carisbad, CA, USA), containing $10 \%$ dimethyl sulfoxide $(1.4 \mathrm{~mol} / \mathrm{L}$; CryoSure-DMSO; WakChemie Medical GmbH, Steinbach, Germany), and $10 \%$ serum substitute supplement (SSS; Irvine Scientific, Santa Ana, CA, USA). Nunc CryoTubes were filled with $1.7 \mathrm{~mL}$ cold medium $\left(0{ }^{\circ} \mathrm{C}\right)$ and a cortex fragment. Instead of using the program as described for the IceCube (14S-A, SY-LAB, Neupurkersdorf, Austria) in the original protocol [13], the CryoTubes were frozen in the CryoLogic programmable temperature controller using the program as stated under "Cryopreservation protocol $\mathrm{A}_{\mathrm{C}}$." This freezing protocol was comparable to the original protocol, expect for an incubation step in the programmable freezer at $2{ }^{\circ} \mathrm{C}$ for $40 \mathrm{~min}$, the seeding temperature $\left(-9\right.$ instead of $-6{ }^{\circ} \mathrm{C}$, allowing us to freeze tissue according to protocol $\mathrm{A}_{\mathrm{C}}$ and $\mathrm{B}_{\mathrm{C}}$ simultaneously and in the same Cryologic freezing device) and the speed at which the temperature was lowered after reaching $-40{ }^{\circ} \mathrm{C}$ $\left(8.5^{\circ} \mathrm{C} / \mathrm{min}\right.$ to $-120^{\circ} \mathrm{C}$ versus $10{ }^{\circ} \mathrm{C} / \mathrm{min}$ to $-140{ }^{\circ} \mathrm{C}$ in the original protocol).

\section{Thawing protocol $B_{T}$}

Thawing protocol $\mathrm{B}_{\mathrm{T}}$ was based on continuous dilution of the cryoprotectant [20]. The CryoTubes were removed from the liquid nitrogen, warmed for $30 \mathrm{~s}$ at room temperature, and placed in a $37^{\circ} \mathrm{C}$ water bath for $2 \mathrm{~min}$. Directly after thawing, the ovarian cortex fragments were transferred to a solution of $10 \mathrm{~mL}$ Dulbecco's Phosphate-Buffered Saline (DPBS; Gibco), $0.75 \mathrm{M}$ sucrose (MP Biomedicals, Eschwege, Germany), $10 \%$ serum substitute supplement (SSS; Irvine
Scientific, Santa Ana, USA), and $0.1 \mathrm{mg} / \mathrm{mL}$ Pen/Strep (Lonza, Basel, Switzerland) and incubated under continuous agitation for $15 \mathrm{~min}$ at room temperature. This first washing solution had an osmolality of $1.2 \mathrm{Osmol} / \mathrm{kg}$. After this first incubation step, $50 \mathrm{~mL}$ of a solution consisting of DPBS with $10 \% \mathrm{SSS}$ and $0.1 \mathrm{mg} / \mathrm{mL}$ Pen/Strep was added using a pump set at $100 \mathrm{~mL} / \mathrm{h}$. At complete infusion $(30 \mathrm{~min})$, the cortex fragments were transferred into a $5 \mathrm{~mL}$ pre-warmed $\left(37^{\circ} \mathrm{C}\right)$ Hepes-buffered medium (Gamete, Cook Medical Europe LTD, Limerick, Ireland) and incubated for another $15 \mathrm{~min}$. After repeating this step once, the tissue was washed three times for $5 \mathrm{~min}$ in tissue culture medium used for the glucose uptake assay (described below). In total, this resulted in a thawing procedure of approximately $1.5 \mathrm{~h}$.

\section{Outcome measures}

For the control as well as the four study arms, the overall ovarian tissue viability, follicle viability, and tissue morphology were examined using the following methods.

\section{Glucose uptake assay}

The ovarian tissue's overall viability was assessed using a glucose uptake assay we described previously [22]. This assay quantitatively measures the glucose uptake by ovarian tissue during in vitro culture. Glucose uptake has been shown to be inversely correlated with the extent of (cryo)damage the tissue has sustained [22]. This assay has also been successfully used for determining the viability of human ovarian cortex tissue after cryopreservation [21].

For each individual measurement, four cortex biopsies were prepared using a 3-mm-diameter biopsy punch (Pfm Medical ag, Cologne, Germany). For each of these four ovarian biopsies, glucose uptake was determined by culturing them separately in $2 \mathrm{~mL}$ Dulbecco's Modified Eagle Medium High Glucose (4.5 g/L) with L-Glutamine (DMEM, PAA Laboratories) supplemented with $10 \%$ fetal bovine serum (FBS; PAA Laboratories GmbH, Cölbe, Germany) and $0.1 \%$ Pen/Strep (GIBCO; 10.000 units penicillin $/ \mathrm{mL}$ and $10.000 \mu \mathrm{g}$ streptomycin $/ \mathrm{mL}$ ) in a 24 -well plate (TPP, Trasadingen, Switzerland) at $37{ }^{\circ} \mathrm{C}$ in humidified air with $5 \% \mathrm{CO}_{2}$. The $2 \mathrm{~mL}$ of conditioned culture medium was collected from each individual biopsy, and replaced by fresh medium at day 4 and again collected at day 7 , when the culture was ended. After culture, the biopsies were weighed separately and the glucose content of unconditioned medium (control) and of the conditioned medium after 4 or 7 days of culture were measured using an Architect i2000 system (Abbott Diagnostics, IL, USA). The glucose uptake of each biopsy during the culture period from day $0-4$ and day 4-7 was determined by subtracting the glucose content of the conditioned medium from the unconditioned control medium. 
Glucose uptake was corrected for the weight $(\mathrm{mg})$ of the biopsy and the duration (h) of the culture period [21, 22]. Then, for each series of four biopsies cultured under the same conditions, the mean glucose uptake/milligram/hour (nmol) was calculated representing an individual measurement on day 0 4, day 4-7, and (combined) day 0 to 7.

\section{Percentage of living follicles}

The viability of ovarian follicles was assessed in fresh tissue, or immediately after thawing, using a neutral red (NR) assay modified from Kristensen et al. [23]. With this metabolic assay, based on the ability of living cells to incorporate and bind neutral red in their lysosomes [24], living follicles were stained red, whereas dead follicles remained transparent (Fig. 1). A total of 10-15 fragments $\left(<1 \mathrm{~mm}^{3}\right)$ were cut from 3-4 ovarian cortex fragments of $5 \times 5 \times 1 \mathrm{~mm}$, and incubated in $5 \mathrm{~mL}$ Ultraculture (Lonza) supplemented with $1 \mathrm{mg} / \mathrm{mL}$ Collagenase type IA (Sigma-Aldrich, Steinheim, Germany) at $37^{\circ} \mathrm{C}$ for $1 \mathrm{~h}$ to soften and partially dissolve the tissue. Subsequently, the suspension was centrifuged at $400 \times g$ for 5 min after which the tissue pellet was resuspended in NR solution, consisting of $4.8 \mathrm{~mL}$ McCoy medium (Gibco, Life Technologies, New York, USA), $75 \mu \mathrm{L}$ neutral red (to a final concentration of $50 \mathrm{mg} / \mathrm{mL}$; Sigma-Aldrich), $2 \mu \mathrm{L}$ Albuman (200 g/L; Sanquin, Amsterdam, the Netherlands), $50 \mu \mathrm{L}$ Insulin-Transferrin-Selenium (ITS-G, Gibco), 200 units penicillin (Gibco), and $200 \mu \mathrm{g}$ streptomycin (Gibco). The NR suspension containing the ovarian tissue was incubated for $90 \mathrm{~min}$ at $37{ }^{\circ} \mathrm{C}$ in humidified air with $5 \% \mathrm{CO}_{2}$. Next, the partly dissolved tissue fragments were removed from the bottom of the tube and placed on a glass slide. By gently pressing a cover slip on the softened tissue fragments, a squash preparation was obtained. Living (stained red) as well as dead (nonstained) follicles were counted in this preparation using light microscopy. The percentage of living follicles was documented for each condition for which a NR viability assay was performed, provided that at least 20 follicles could be analyzed. Results obtained from samples with less than 20 follicles were considered unreliable and therefore excluded from further analysis. Using these criteria, the percentage of living follicles could be determined in the tissue of 16 patients while the tissue of the five remaining patients was excluded.

\section{Tissue morphology}

For histology, cortex fragments of $5 \times 5 \times 1 \mathrm{~mm}$ from 18 patients were fixed in Bouin's solution (Sigma-Aldrich) and subsequently embedded in paraffin wax. Eight $\mu \mathrm{m}$ hematoxylin- and eosin-stained sections were examined using light microscopy and photographed. For each fragment, three sections were evaluated. Sections were separated by $100 \mu \mathrm{m}$ of tissue to prevent counting the same pre-antral follicle twice. Follicles were scored as morphologically normal or degenerated (in case of cytoplasmatic shrinkage, disorganized granulosa cells, pyknotic nuclei) and categorized as primordial/primary, secondary, or antral according to a predefined criteria [25]. We focused at the percentage of degenerated/ dead follicles rather than the tot number of follicles observed per study arm as the density of follicles in various parts of the cortex of the same ovary may vary considerably [26].

\section{Statistical methods}

A linear-mixed model for repeated measurements was used to study differences between protocols used for cryopreservation and for thawing on each of variables of the viability of human ovarian tissue, separately. In this way, it is possible to find small within-subject differences relative to a large betweensubject (biological) variation. The dependent variable was the glucose uptake and the percentage living follicles, respectively. The independent categorical variables were cryopreservation (two protocols $\mathrm{A}_{\mathrm{C}}, \mathrm{B}_{\mathrm{C}}$ ), thawing (two protocols $\mathrm{A}_{\mathrm{T}}, \mathrm{B}_{\mathrm{T}}$ ), and the time point of measurement (two levels day 0-4, day 4-7). The intercept of each patient was treated as a random variable, in order to allow different levels for different

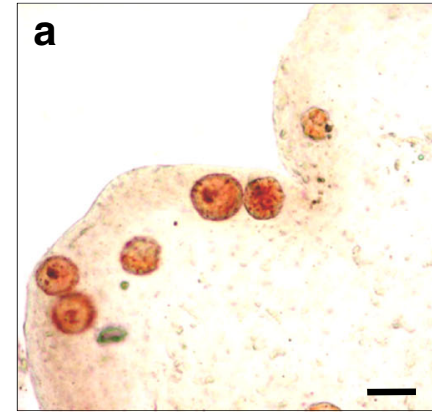

Fig. 1 Follicles visualized by neutral red staining. a Overview of living follicles of various sizes as visualized with the neutral red viability stain. Due to the thickness of the squash preparation, not all follicles are in
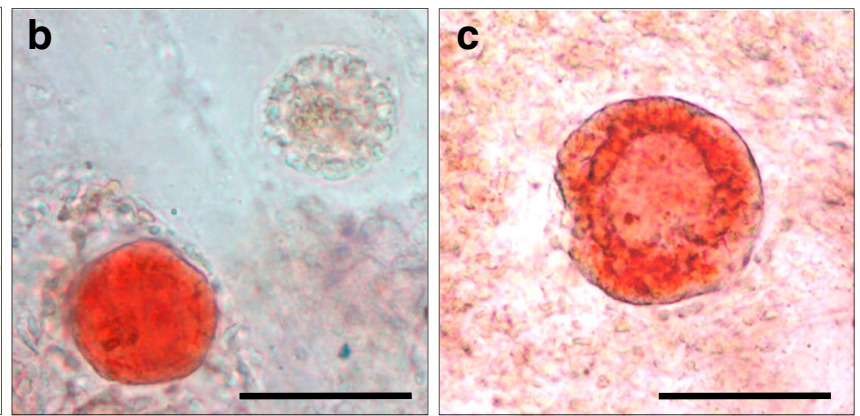

focus. b Fresh tissue with a viable follicle (red) and dead follicle (transparent). c Close-up of a living follicle. Bars represent $200 \mu \mathrm{M}$ 
patients. Initially, all interaction terms between the categorical variables were included in the linear part of the model. However, these terms were omitted from the final model presented as these did not statistically significant improve the fit to the data (Likelihood-Ratio test). The estimated mean differences between the levels of each variable with the appropriate $95 \%$ confidence interval are presented. Statistical analyses were performed by using SAS ${ }^{\circledR}$ version 9.2 for Windows (SAS institute Inc. Cary, NC, USA).

\section{Results}

\section{Patient characteristics}

A total of 21 women (median age 40 years; range 32-45) participated in this study. Twenty women were healthy BRCA 1 or 2 mutation carriers who did not receive prior gonadotoxic therapy, whereas one woman had her ovaries removed because of breast cancer after chemotherapy. Ten women used contraceptives (oral, $n=5$; intrauterine device, $n=4$; NuvaRing, $n=1$ ), 10 had regular menstrual cycles, and one had had a hysterectomy in the past. This last participant was considered premenopausal as she had a normal level of anti-Müllerian hormone (AMH $3.2 \mu \mathrm{g} / \mathrm{L}$ ) without menopausal symptoms. For four women, only part of the study arms could be evaluated, because of a small ovary $(n=2)$, the presence of large follicles $(n=1)$, or cauterization damage $(n=1)$.

\section{Glucose uptake}

In Table 1, the observed median glucose uptake per milligram ovarian tissue per hour of culture is presented for fresh ovarian tissue, and for ovarian tissue subjected to one of the four different combinations of freezing $\left(\mathrm{A}_{\mathrm{C}}\right.$ and $\left.\mathrm{B}_{\mathrm{C}}\right)$ and thawing protocols $\left(\mathrm{A}_{\mathrm{T}}\right.$ and $\left.\mathrm{B}_{\mathrm{T}}\right)$, expressed as mean of 4 separately assayed cortex fragments per individual patient $(n=18-21$; see Table 1). Biopsies showed no difference in weight between cultured biopsies and fresh biopsies (data not shown).

Glucose uptake was comparable for the day 0-4 culture and the 4-7 day culture period and was not significantly different (Tables 1 and 2). For reasons of clarity, only the day $0-4$ results are described.

As expected, the highest glucose uptake was found for fresh tissue $(23.5 \mathrm{nmol} / \mathrm{mg} / \mathrm{h})$. Note that the range of glucose uptake by the tissues derived from individual patients was large (range $8.3-32.7 \mathrm{nmol} / \mathrm{mg} / \mathrm{h}$ ), demonstrating a large inter-patient variability. Independent of the thawing protocol, tissue cryopreserved according to protocol $\mathrm{B}_{\mathrm{C}}$ had a significantly higher glucose uptake when compared to $\mathrm{A}_{\mathrm{C}}\left(\mathrm{B}_{\mathrm{C}} \mathrm{B}_{\mathrm{T}}\right.$ 16.3 and $B_{C} A_{T} 17.3$ vs $A_{C} B_{T} 7.1$ and $A_{C} A_{T} 8.7 \mathrm{nmol} / \mathrm{mg} / \mathrm{h}$, Table 1). In Table 2, the estimated differences of the glucose uptake between the cryopreservation and thawing protocolsas obtained by a linear-mixed model for repeated measurements - are presented. According to this model, tissue that was cryopreserved using protocol $\mathrm{B}_{\mathrm{C}}$ showed a statistically significant higher glucose uptake $(6.8 \mathrm{nmol} / \mathrm{mg} / \mathrm{h}$ higher; $p<0.001)$ than tissue cryopreserved using protocol $\mathrm{A}_{\mathrm{C}}$ (Table 2). A small difference in glucose uptake $(1.7 \mathrm{nmol} /$ $\mathrm{mg} / \mathrm{h}$ ) was found in favor of the shorter thawing protocol A ${ }_{\mathrm{T}}$ when compared to $\mathrm{B}_{\mathrm{T}}$, but this difference did not reach statistical significance ( $p=0.051$; Table 2$)$.

To eliminate the large inter-patient variability in glucose uptake mentioned previously, we also expressed glucose uptake of frozen and thawed ovarian tissue as a percentage of the glucose uptake by fresh control tissue (Fig. 2). As already observed for the absolute values of glucose uptake levels in Table 1, the decrease in glucose uptake was considerably less in tissue frozen via the $\mathrm{B}_{\mathrm{C}}$ protocol (19.8 and $13.5 \%$ decrease for the $\mathrm{B}_{\mathrm{C}} \mathrm{B}_{\mathrm{T}}$ and $\mathrm{B}_{\mathrm{C}} \mathrm{A}_{\mathrm{T}}$ protocol, respectively), compared to tissue frozen via the $A_{C}$ protocol (50.4 and $56.8 \%$ decrease for the $A_{C} B_{T}$ and $A_{C} A_{T}$ protocol, respectively). The decrease in glucose uptake was independent of the thawing protocol. Remarkably, we observed a post freeze/thaw increase in glucose uptake in comparison to the glucose uptake by the corresponding fresh control tissue in small subset of patients (1-5 patients per freeze/thaw protocol combination).

\section{Percentage of living follicles}

A mean number of 80 follicles (SD 49) was evaluated in each ovarian tissue sample using the neutral red viability assay after having excluded samples with less than 20 follicles $(n=21$ out of $n=98$ ). Similar numbers of follicles could be counted before and after excluding the samples with less than 20 follicles for each of the study arms (data not shown). In Table 1, the observed percentages of living follicles obtained with the neutral red viability assay are presented. In accordance with the results regarding the tissue's glucose uptake, tissue that was cryopreserved according to protocol $\mathrm{B}_{\mathrm{C}}$ showed a statistically significant higher percentage of living follicles when compared to tissue cryopreserved according to protocol $\mathrm{A}_{\mathrm{C}}$ ( $\mathrm{p}=0.002$; Table 2 and Fig. 3). Analogously to the results of the glucose uptake assay, we observed no significant difference between thawing protocols $A_{T}$ and $B_{T}$ with respect to the percentage of living follicles ( $\mathrm{p}=0.651$; Table 2$)$.

We found the correlation between glucose uptake and follicle viability to be poor in all four study arms during $0-4$ and 4-7 day culture (Spearman's correlation $<0.3, p$ values 0.33 $0.99)$.

\section{Follicle morphology}

Histological examination of the hematoxylin- and eosin-stained sections from fresh tissue revealed that $99 \%$ of the follicles 
Table 1 The observed median (range) of the glucose uptake and the percentage of living follicles for each combination of cryopreservation protocol and thawing protocol

\begin{tabular}{|c|c|c|c|c|c|c|c|c|c|}
\hline \multicolumn{2}{|l|}{ Protocol } & \multicolumn{5}{|c|}{ Glucose uptake (nmol/mg/h) } & \multicolumn{3}{|c|}{ Living follicles (\%) } \\
\hline \multirow{2}{*}{$\begin{array}{l}\text { Cryopreservation } \\
\text { Fresh }\end{array}$} & \multirow{2}{*}{$\begin{array}{l}\text { Thawing } \\
\text { Fresh }\end{array}$} & \multirow{2}{*}{$\begin{array}{l}N \\
21\end{array}$} & \multicolumn{2}{|c|}{ Culture days $0-4$ median (range) } & \multicolumn{2}{|c|}{ Culture days 4-7 median (range) } & \multirow{2}{*}{$\begin{array}{l}N \\
11\end{array}$} & \multicolumn{2}{|c|}{ median (range) } \\
\hline & & & 23.5 & $(8.3-32.7)$ & 20.3 & $(8.8-28.3)$ & & 94.5 & $(89.1-98.3)$ \\
\hline $\mathrm{A}_{\mathrm{C}}$ & $\mathrm{A}_{\mathrm{T}}$ & 18 & 8.7 & $(-0.5-29.5)$ & 8.1 & $(1.0-26.8)$ & 16 & 72.5 & $(26.3-95.4)$ \\
\hline $\mathrm{A}_{\mathrm{C}}$ & $\mathrm{B}_{\mathrm{T}}$ & 19 & 7.1 & $(-0.5-25.3)$ & 6.5 & $(-5.5-29.0)$ & 15 & 76.6 & $(20.0-95.7)$ \\
\hline $\mathrm{B}_{\mathrm{C}}$ & $\mathrm{A}_{\mathrm{T}}$ & 20 & 17.3 & $(0.8-31.3)$ & 18.2 & $(0.5-30.9)$ & 17 & 87.5 & $(65.5-96.1)$ \\
\hline $\mathrm{B}_{\mathrm{C}}$ & $\mathrm{B}_{\mathrm{T}}$ & 20 & 16.3 & $(1.9-24.1)$ & 16.8 & $(3.2-23.9)$ & 14 & 88.7 & $(18.2-100.0)$ \\
\hline
\end{tabular}

The glucose uptake is expressed in nanomolars per milligram of ovarian cortex tissue per hour of culture. Follicle viability assessment by the neutral red staining was performed in fresh tissue or immediately after thawing. The percentage of living follicles was only determined in preparations in which at least 20 follicles could be counted

$A_{C}$ cryopreservation protocol A, $A_{T}$ thawing protocol A, $B_{C}$ cryopreservation protocol B, $B_{T}$ thawing protocol B, $N$ number of patients

were morphologically normal. After cryopreservation/thawing according to the four study arms, $89 \%\left(\mathrm{~A}_{\mathrm{C}} \mathrm{A}_{\mathrm{T}}\right), 85 \%\left(\mathrm{~A}_{\mathrm{C}} \mathrm{B}_{\mathrm{T}}\right)$, $93 \%\left(\mathrm{~B}_{\mathrm{C}} \mathrm{A}_{\mathrm{T}}\right)$, and $84 \%\left(\mathrm{~B}_{\mathrm{C}} \mathrm{B}_{\mathrm{T}}\right)$ of the primordial/primary follicles were morphologically normal, whereas the remaining primordial/primary follicles showed cytoplasm shrinkage, disorganized granulosa cells, or pyknotic nuclei as a sign of follicle degeneration (Fig. 4). The majority of the total of 2039 follicles observed were in the primordial or primary stages. For each of the four study arms as well as the fresh tissue, 2$3 \%$ of the follicles were in their secondary or antral stages. The percentage of degenerated secondary follicles was similar to the percentage degenerated primordial/primary follicles. Most of the follicles $(>90 \%)$ in the antral stage showed some signs of degeneration after freezing and thawing.

\section{Discussion}

Currently, many different protocols are used worldwide for the cryopreservation and subsequent thawing of human ovarian tissue intended for fertility preservation. Little is known regarding the relative efficiency and efficacy of these protocols. To investigate this matter, we compared two human ovarian tissue slow-freezing cryopreservation and thawing protocols that have both proven to be clinically successful. Our explicit goal was to explore any possible differences in efficiency and efficacy between protocols that are clinically used, rather than to identify a superior freezing/thawing protocol.

The glucose uptake by ovarian tissue derived from different patients showed a large degree of variability (Table 1). This was also observed in a previous study [21]. These differences may be explained by ovarian cortex tissue heterogeneity between different patients or, alternatively, reflect differences in the initial viability of the tissues due to differing periods of warm ischemia after the surgical removal of the ovary.

We observed significant differences between two protocols for freezing human ovarian tissue with regard to their effect on glucose uptake. We have previously shown that glucose uptake is strongly correlated with tissue
Table 2 The estimated mean difference $(95 \%$ confidence interval (CI)) of the glucose uptake and the percentage of living follicles between the cryopreservation protocols, thawing protocols, and culture periods, using a linear-mixed model for repeated measurements

\begin{tabular}{|c|c|c|c|c|c|c|c|}
\hline & \multirow[t]{3}{*}{ Protocol/day } & \multicolumn{3}{|c|}{ Glucose uptake (nmol/mg/h) } & \multicolumn{3}{|c|}{ Living follicles (\%) } \\
\hline & & \multicolumn{3}{|c|}{ Estimated difference } & \multicolumn{3}{|c|}{ Estimated difference } \\
\hline & & mean & $5 \% \mathrm{CI})$ & $p$ value & mean & $5 \% \mathrm{CI})$ & $p$ value \\
\hline \multirow[t]{2}{*}{ Cryopreservation } & $\mathrm{A}_{\mathrm{C}}$ & 0.0 & Reference & & 0.0 & Reference & \\
\hline & $\mathrm{B}_{\mathrm{C}}$ & 6.8 & $(5.0 ; 8.6)$ & $<0.001$ & 11.3 & $(4.6 ; 18.0)$ & 0.002 \\
\hline \multirow[t]{2}{*}{ Thawing } & $\mathrm{A}_{\mathrm{T}}$ & 0.0 & Reference & & 0.0 & Reference & \\
\hline & $\mathrm{B}_{\mathrm{T}}$ & -1.7 & $(-3.5 ; 0.0)$ & 0.051 & -1.5 & $(-8.1 ; 5.1)$ & 0.651 \\
\hline \multirow[t]{2}{*}{ Culture period } & Day $0-4$ & 0.2 & $(-1.6 ; 1.9)$ & 0.842 & & & \\
\hline & Day 4-7 & 0.0 & Reference & & & & \\
\hline
\end{tabular}

$A_{C}$ cryopreservation protocol A, $A_{T}$ thawing protocol A, $B_{C}$ cryopreservation protocol B, $B_{T}$ thawing protocol B 
Fig. 2 Glucose uptake by ovarian cortex tissue after different combinations of cryopreservation and thawing protocols. Total glucose uptake during 7 days of culture is expressed as a percentage of glucose uptake by fresh (=nonfrozen, non-thawed) ovarian cortex tissue of the same patient. Mean and $95 \%$ confidence interval are indicated. $A_{C}$ cryopreservation protocol A, $A_{T}$ thawing protocol $\mathrm{A}, B_{C}$ cryopreservation protocol $\mathrm{B}, B_{T}$ thawing protocol $\mathrm{B}$

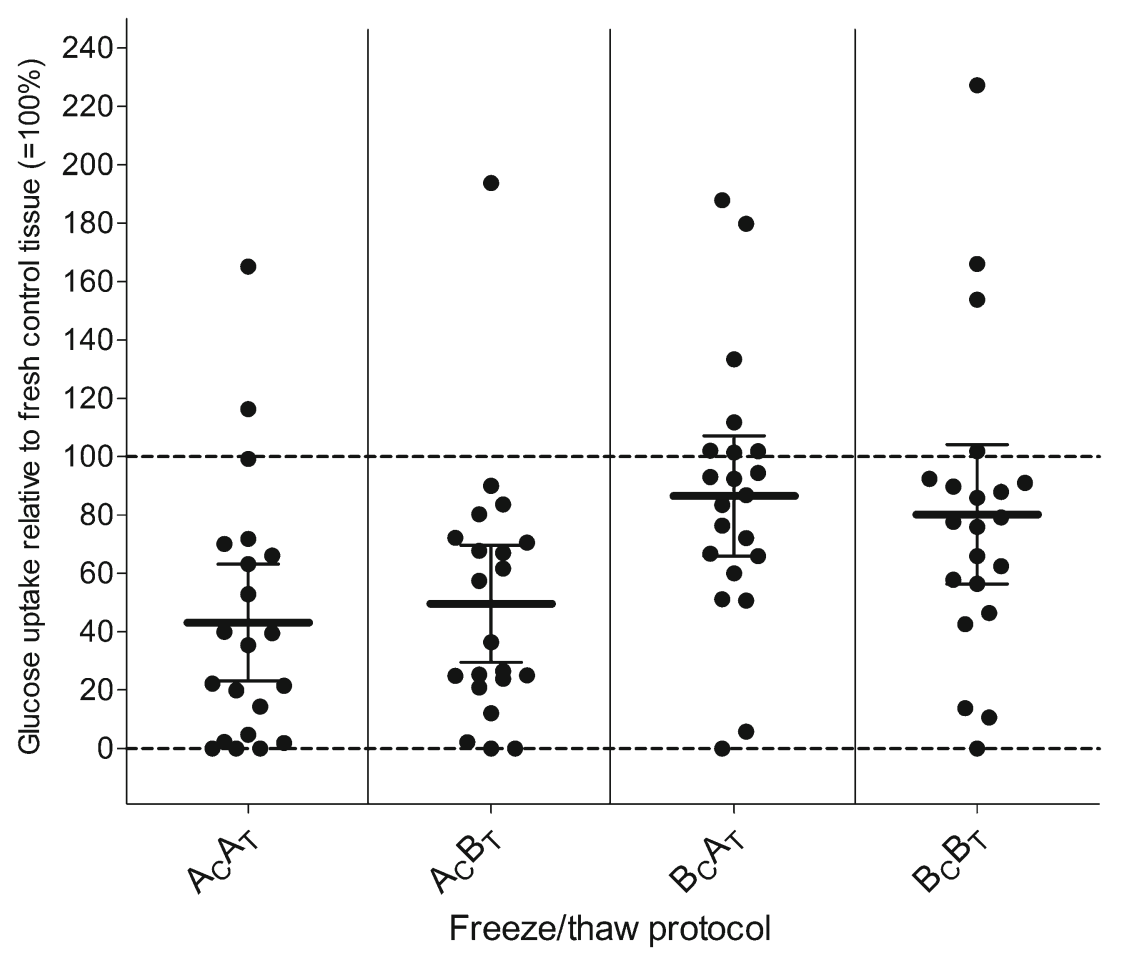

Several differences between cryopreservation protocols $\mathrm{A}_{\mathrm{C}}$ and $\mathrm{B}_{\mathrm{C}}$ can be identified; the major one being the use of ethylene glycol as a cryoprotectant in protocol $\mathrm{A}_{\mathrm{C}}$ and DMSO in protocol $\mathrm{B}_{\mathrm{C}}$.

Previous studies have compared DMSO and ethylene glycol-in the absence or presence of sucrose - in slow-freezing protocols for the cryopreservation of animal or human ovarian tissue or isolated follicles. In accordance with the results of the current study, a better follicle morphology and a higher percentage of living follicles were found after cryopreservation using DMSO when compared to ethylene glycol for human, sheep, or goat ovarian tissue [27-30]. However, DMSO did not improve the preservation of the follicle survival and ultrastructure when compared to ethylene glycol in bovine or agouti tissue [31,32].

The two thawing procedures we used were very different with respect to the composition of the thawing solutions, as well as the length of the thawing process. This makes it difficult to separately evaluate the effects of the factor time and of the various components used in the thawing solution and, consequently, to pinpoint the individual contribution of these two factors on the efficacy of the thawing procedure. The exact reason for the effects on thawing efficacy notwithstanding, it is clear that protocol $A_{T}$ was more time effective and required less human effort and material than protocol $B_{T}$ and can therefore be considered more efficient.

Interestingly, the percentage of morphologically normal follicles was generally higher than the percentage of viable follicles. This may due to the fact that follicles that appear
Fig. 3 Percentage of living follicles in ovarian tissue after different combinations of cryopreservation- and thawing protocols. Follicle viability was assessed by neutral red staining. Results are expressed as percentage living follicles of the total number of follicles that was counted, and expressed as mean and $95 \%$ confidence interval 
Fig. 4 Follicle morphology after different combinations of cryopreservation and thawing protocols. Follicle morphology was determined by analysis of hematoxylin-/eosin-stained sections of ovarian cortex tissue before (panel a) and after cryopreservation and thawing according to cryopreservation protocol $\mathrm{A}_{\mathrm{c}} \mathrm{A}_{\mathrm{T}}$ (panel $\mathbf{b}$ ), protocol $\mathrm{A}_{\mathrm{c}} \mathrm{B}_{\mathrm{T}}$ (panel c), protocol $\mathrm{B}_{\mathrm{c}} \mathrm{B}_{\mathrm{T}}$ (panel d), and protocol $\mathrm{B}_{\mathrm{c}} \mathrm{A}_{\mathrm{T}}$ (panel e). In panels $\mathbf{b}-\mathbf{e}$, the follicles with pyknotic nuclei (black arrow heads) and cytoplasmic shrinkage (white arrow heads) are indicated. Bars represent $100 \mu \mathrm{M}$
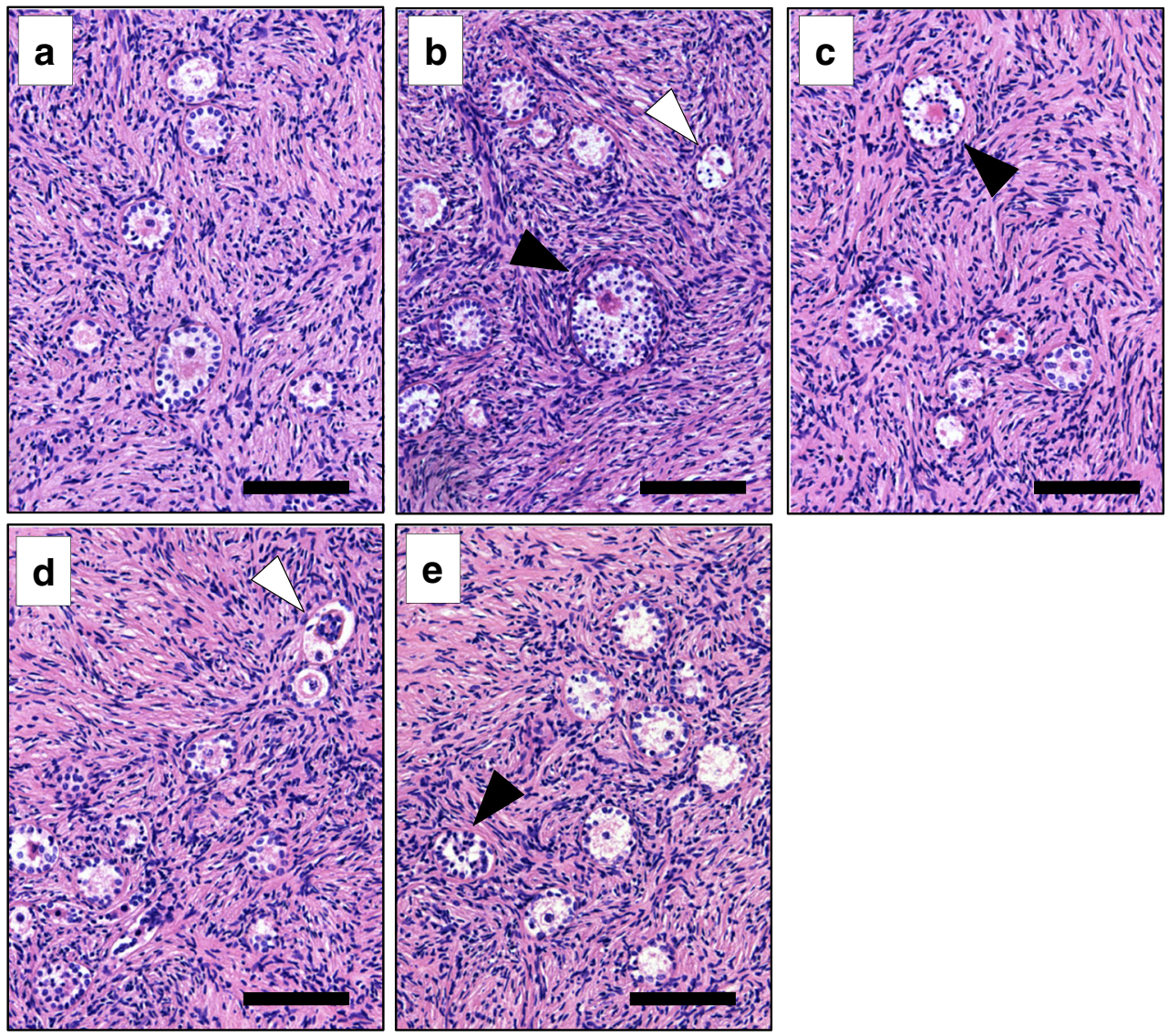

morphologically normal are, due to the freezing and thawing procedure, not metabolically active anymore.

We found no correlation between follicle viability and levels of glucose uptake. This is not surprising as stromal cells contribute by far the most to the cellular volume of the ovarian cortex. As a consequence result from the glucose uptake, assay will predominantly reflect the viability of the stromal compartment. We have shown that stromal cells are more sensitive to the damaging effects of the freeze thaw/procedure than follicles (as demonstrated by the decrease in glucose uptake after freeze/ thawing, and the decrease in viable follicles, respectively). Similar findings were reported by Kim et al. [33] and Sanfilippo et al. [16]. Stromal cells are essential for the neovascularization of an ovarian graft after autotransplantation [34] and thus for follicle growth and maturation after transplantation. In this context, including viability of the stromal compartment in the evaluation of cryopreservation and thawing protocols, it is essential.

Several factors may have influenced the outcome of our study. First, the donors of ovarian tissue (BRCA mutation carriers) are considerably older than the population eligible for cryopreservation of ovarian tissue. Several authors have shown that the composition and structure of ovarian tissue alters as a result of aging $[35,36]$. Consequently, the effects of various cryopreservation and thawing protocols should be further evaluated in a population of young patients applying for fertility preservation. Secondly, the percentage of living follicles observed after NR stain may be overestimated as the dead, non-stained follicles are less visible and might be missed during analysis. Finally, our experiments included combining a freezing solution containing DMSO and a thawing solution with ethylene glycol. Obviously, this will never be the combination of choice, as this will result in different rates of efflux and influx of two different cryoprotectants into the cells. However, we decided to test these combinations to study the effect of freezing and thawing separately.

Cryopreservation and thawing protocols might be modified or optimized over time. For example, human ovarian tissue was initially cryopreserved without a protein source in the cryopreservation medium in protocol $\mathrm{A}_{\mathrm{C}} \mathrm{A}_{\mathrm{T}}$ [18]. In a more recent overview presented by the same group, however, the otherwise identical cryopreservation medium was described to contain $1 \%$ serum albumin [19]. The impact of this change in protocol was not evaluated by the team using the protocol in clinical practice and it is therefore unknown to what extent this modification would have changed the results of our current study. Obviously, it remains unknown from our data to what extent the impairment of the ovarian tissue viability observed in this study influences pregnancy rates after autotransplantation. 
In conclusion, we demonstrate considerable differences in the effects of two clinically successful freezing and thawing protocols on the viability of human ovarian tissue, in a series of 21 patients. More precisely, the efficacy of the freezing protocols and the efficiency of the thawing procedures proved to be very different. To the best of our knowledge, this is the first report on human ovarian tissue cryopreservation that provides information on the effectiveness of the cryopreservation and the thawing procedures separately. Once again, we would like to emphasize that it was not our intention to discover the ultimate cryopreservation protocol. Rather, we want to stress that there actually are, with regard to efficacy and efficiency, considerable differences between clinically successful cryopreservation protocols. As a consequence, further optimization of these protocols may lead to even higher success rates.

Acknowledgments Unconditional funding was received from the Radboud Institute for Health Sciences (RIHS), the KiKa Foundation, and Merck Serono.

\section{Compliance with ethical standards}

Conflict of interest The authors declare that they have no conflict of interest.

Open Access This article is distributed under the terms of the Creative Commons Attribution 4.0 International License (http:// creativecommons.org/licenses/by/4.0/), which permits unrestricted use, distribution, and reproduction in any medium, provided you give appropriate credit to the original author(s) and the source, provide a link to the Creative Commons license, and indicate if changes were made.

\section{References}

1. Aben KK, van Gaal C, van Gils NA, van der Graaf WT, Zielhuis GA. Cancer in adolescents and young adults (15-29 years): a population-based study in the Netherlands 1989-2009. Acta Oncol. 2012;51:922-33.

2. Lobo RA. Potential options for preservation of fertility in women. N Engl J Med. 2005;353:64-73.

3. Salama M, Winkler K, Murach KF, Seeber B, Ziehr SC, Wildt L. Female fertility loss and preservation: threats and opportunities. Ann Oncol. 2013;24:598-608.

4. Jadoul P, Dolmans MM, Donnez J. Fertility preservation in girls during childhood: is it feasible, efficient and safe and to whom should it be proposed? Hum Reprod Update. 2010;16:617-30.

5. Donnez J, Dolmans MM, Pellicer A, Diaz-Garcia C, Sanchez Serrano M, Schmidt KT, et al. Restoration of ovarian activity and pregnancy after transplantation of cryopreserved ovarian tissue: a review of 60 cases of reimplantation. Fertil Steril. 2013;99:1503-13.

6. Donnez J, Dolmans MM. Transplantation of ovarian tissue. Best Pract Res Clin Obstet Gynaecol. 2014;28:1188-97.

7. Donnez J, Dolmans MM. Ovarian cortex transplantation: 60 reported live births brings the success and worldwide expansion of the technique towards routine clinical practice. J Assist Reprod Genet. 2015;32:1167-70.

8. Radford JA, Lieberman BA, Brison DR, Smith AR, Critchlow JD, Russell SA, et al. Orthotopic reimplantation of cryopreserved ovarian cortical strips after high-dose chemotherapy for Hodgkin's lymphoma. Lancet. 2001;357:1172-5.

9. Schmidt KL, Ernst E, Byskov AG, Nyboe Andersen A, Yding Andersen C. Survival of primordial follicles following prolonged transportation of ovarian tissue prior to cryopreservation. Hum Reprod. 2003;18:2654-9.

10. Donnez J, Dolmans MM, Demylle D, Jadoul P, Pirard C, Squifflet J, et al. Livebirth after orthotopic transplantation of cryopreserved ovarian tissue. Lancet. 2004;364:1405-10.

11. Oktay K, Oktem O. Ovarian cryopreservation and transplantation for fertility preservation for medical indications: report of an ongoing experience. Fertil Steril. 2010;93:762-8.

12. Stern CJ, Toledo MG, Hale LG, Gook DA, Edgar DH. The first Australian experience of heterotopic grafting of cryopreserved ovarian tissue: evidence of establishment of normal ovarian function. Aust N Z J Obstet Gynaecol. 2011;51:268-75.

13. Dittrich R, Lotz L, Keck G, Hoffmann I, Mueller A, Beckmann MW, et al. Live birth after ovarian tissue autotransplantation following overnight transportation before cryopreservation. Fertil Steril. 2012;97:387-30.

14. Demeestere I, Simon P, Dedeken L, Moffa F, Tsépélidis S, Brachet C, et al. Live birth after autograft of ovarian tissue cryopreserved during childhood. Hum Reprod. 2015;30:2107-9.

15. Gracia CR, Chang J, Kondapalli L, Prewitt M, Carlson CA, Mattei P, et al. Ovarian tissue cryopreservation for fertility preservation in cancer patients: successful establishment and feasibility of a multidisciplinary collaboration. J Assist Reprod Genet. 2012;29:495-502.

16. Sanfilippo S, Canis M, Romero S, Sion B, Dechelotte P, Pouly JL, et al. Quality and functionality of human ovarian tissue after cryopreservation using an original slow freezing procedure. J Assist Reprod Genet. 2013;30:25-34.

17. Rodriguez-Wallberg KA, Karlström PO, Rezapour M, Castellanos E, Hreinsson J, Rasmussen C, et al. Full-term newborn after repeated ovarian tissue transplants in a patient treated for Ewing sarcoma by sterilizing pelvic irradiation and chemotherapy. Acta Obstet Gynecol Scand. 2015;94:324-8.

18. Schmidt KL, Yding Andersen C, Starup J, Loft A, Byskov AG, Nyboe Andersen A. Orthotopic autotransplantation of cryopreserved ovarian tissue to a woman cured of cancer - follicular growth, steroid production and oocyte retrieval. Reprod Biomed Online. 2004;8:448-43.

19. Rosendahl M, Schmidt KT, Ernst E, Rasmussen PE, Loft A, Byskov AG, et al. Cryopreservation of ovarian tissue for a decade in Denmark: a view of the technique. Reprod Biomed Online. 2011;22:162-71.

20. Isachenko V, Isachenko E, Reinsberg J, Montag M, Braun F, van der Ven H. Cryopreservation of human ovarian tissue: effect of spontaneous and initiated ice formation. Reprod Biomed Online. 2008; $16: 336-45$.

21. Bastings L, Liebenthron J, Westphal JR, Beerendonk CC, van der Ven $\mathrm{H}$, Meinecke B, et al. Efficacy of ovarian tissue cryopreservation in a major European center. J Assist Reprod Genet. 2014;31: 1003-12.

22. Gerritse R, Beerendonk CC, Westphal JR, Bastings L, Braat DD, Peek R. Glucose/lactate metabolism of cryopreserved intact bovine ovaries as a novel quantitative marker to assess tissue cryodamage. Reprod Biomed Online. 2011;23:755-64.

23. Kristensen SG, Rasmussen A, Byskov AG, Andersen CY. Isolation of pre-antral follicles from human ovarian medulla tissue. Hum Reprod. 2011;26:157-66.

24. Repetto G, del Peso A, Zurita JL. Neutral red uptake assay for the estimation of cell viability/cytotoxicity. Nat Protoc. 2008;3:1125-31.

25. Gougeon A. Dynamics of follicular growth in the human: a model from preliminary results. Hum Reprod. 1986;1:81-7.

26. Schmidt KL, Byskov AG, Nyboe Andersen A, Muller J, Yding Andersen C. Density and distribution of primordial follicles in 
single pieces of cortex from 21 patients and in individual pieces of cortex from three entire human ovaries. Hum Reprod. 2003;18: $1158-64$.

27. Santos RR, Rodrigues AP, Costa SH, Silva JR, Matos MH, Lucci $\mathrm{CM}$, et al. Histological and ultrastructural analysis of cryopreserved sheep preantral follicles. Anim Reprod Sci. 2006;91:249-63.

28. Castro SV, de Carvalho AA, da Silva CM, Faustino LR, Campello $\mathrm{CC}$, Lucci CM, et al. Freezing solution containing dimethylsulfoxide and fetal calf serum maintains survival and ultrastructure of goat preantral follicles after cryopreservation and in vitro culture of ovarian tissue. Cell Tissue Res. 2011;346:283-92.

29. Von Schonfeldt V, Chandolia R, Kiesel L, Nieschlag E, Schlatt S, Sonntag B. Assessment of follicular development in cryopreserved primate ovarian tissue by xenografting: prepubertal tissues are less sensitive to the choice of cryoprotectant. Reproduction. 2011;141: 481-90.

30. Camboni A, Van Langendonckt A, Donnez J, Vanacker J, Dolmans MM, Amorim CA. Alginate beads as a tool to handle, cryopreserve and culture isolated human primordial/primary follicles. Cryobiology. 2013;67:64-9.

31. Celestino JJ, dos Santos RR, Lopes CA, Martins FS, Matos MH, Melo MA, et al. Preservation of bovine preantral follicle viability and ultra-structure after cooling and freezing of ovarian tissue. Anim Reprod Sci. 2008;108:309-18.

32. Wanderley LS, Luz HK, Faustino LR, Lima IM, Lopes CA, Silva AR, et al. Ultrastructural features of agouti (Dasyprocta aguti) preantral follicles cryopreserved using dimethyl sulfoxide, ethylene glycol and propanediol. Theriogenology. 2012;77:260-7.

33. Kim SS, Yang HW, Kang HG, Lee HH, Lee HC, Ko DS, et al. Quantitative assessment of ischemic tissue damage in ovarian cortical tissue with or without antioxidant (ascorbic acid) treatment. Fertil Steril. 2004;82:679-85.

34. Demeestere I, Simon P, Emiliani S, Delbaere A, Englert Y. Orthotopic and heterotopic ovarian tissue transplantation. Hum Reprod Update. 2009;15:649-65.

35. Irving J, Clement P. Nonneoplastic lesions of the ovary. In: Kurman R, Hedrick Elleson L, Ronett B, editors. Blaustein's pathology of the female genital tract. 6th ed. New York: Springer Science and Business Media; 2011. p. 600.

36. Titus S, Li F, Stobezki R, Akula K, Unsal E, Jeong K, et al. Impairment of BRCA1-related DNA double-strand break repair leads to ovarian aging in mice and humans. Sci Transl Med. 2013;13:5. 